\title{
Editorial
}

\section{The Challenges of Cognitive Aging: Integrating Approaches from Science to Intergenerational Relationships ${ }^{1}$}

\author{
Peter Whitehouse* \\ Department of Neurology, Case Western Reserve University and University Hospitals Case Medical Center, \\ Cleveland, $\mathrm{OH}, \mathrm{USA}$
}

Accepted 27 March 2013

\begin{abstract}
The individual and social challenges created by population aging and especially the growing number of people labeled with dementia demand new innovative and comprehensive approaches. A broader integrative biology needs to replace reductionist, overly simplistic biomedical solutions that dominate today's scientific discourse, particularly with regards to cognitive aging. Alzheimer's disease is a heterogeneous syndrome characterized more fully at a system rather than molecular level. Coordinated scientific and community responses are needed including new attention to intergenerational relationships, innovative learning organizations, and empowering health practices. The Intergenerational School is a successful public charter school which provides learning opportunities for elementary school children and adults of various ages, including those with dementia. InterWell is a planned primary care and public health practice to be associated with the school. Both represent innovations that balance the sciences and the humanities in address growing social challenges associated with changes in population demographics and climate.
\end{abstract}

Keywords: Dementia, Alzheimer's disease, intergenerational, social relationships, school-based health care

\section{INTRODUCTION}

Cognitive dysfunction challenges individuals of all ages, particularly elders, and societies of all demographics, especially those with rapidly aging populations. Learning impairments of all kinds occur throughout the life course, including notably dementia in children, adults, and seniors. Such cognitive disabilities can limit participation as citizens in a democratic society and create burdens for health care systems and communities around the world. Dementia is defined as loss of cognitive abilities in someone with previ-

\footnotetext{
${ }^{1}$ This article is being co-published in the Journal of Intergenerational Relationships.

*Correspondence to: Peter Whitehouse, MD, PhD, Department of Neurology, Case Western Reserve University and University Hospitals Case Medical Center, Cleveland, OH, USA. E-mail: whitehouse.peter@gmail.com.
}

ously greater intellectual ability [1]; it can be static or progressive. However, dementia is also a metaphor for the challenges we face as a species [2]. Modern life is difficult to comprehend and we have arguably forgotten important lessons from history, like the devastations of war, and we are doing poorly at some of our collective activities of daily living, like eating well and disposing of our wastes [1]. Here I offer a critique of current scientific approaches to brain health and offer a broader model for inquiry, followed by an example of an educational practice which blends the natural and social sciences with the arts and humanities

\section{COGNITIVE AGING AND ITS LABELS}

Cognitive aging is about more than just about loss of abilities. Aging presents challenges that offer 
opportunities for individual and social growth, even the emergence of wisdom. In this article I use a term that captures a full range of life course intellectual changes, i.e., Aging Associated Cognitive Challenges (AACC). Such an invented and then abbreviated term plays on the medical tendency to label aging conditions with variably defined expressions like Aging Associated Memory Impairment (AAMI), Aging-Associated Cognitive Decline (AACD), and Mild Cognitive Impairment (MCI) [1, 3]. This term recognizes that aging is a lifelong process, and that children and adults face AACC as well as elders. The word "challenge" implies that one can adapt to an "impairment" or decline and minimize the impact on quality of life while optimizing gains like becoming more resilient, spiritually developed, and/or wiser.

More label changes in conditions related to cognitive condition are in the works. We are on threshold of DSM-V even eliminating the term dementia itself and replacing it with Major (and Mild for MCI) Neurocognitive Disorders [4]. Dementia can occur in children but youngsters are more commonly affected by words like learning disability and developmental delay. Diagnoses at all ages can lead to appropriate allocation of social resources but also have potentially harmful effects and create lower expectations for success in school or in life. Words, especially diagnostic labels, matter and the stories with which they are associated are essential to our health and humanity [5]. The importance of the invention and evolution of words and stories related to cognitive aging is a major theme in this paper.

\section{ALZHEIMER'S DISEASE}

Alzheimer's disease (AD) constitutes perhaps the greatest socially-perceived threat to healthy aging in the later stages of life. Yet it is as much the concept of $\mathrm{AD}$ that is the threat rather than the actual brain changes that accompany the heterogeneous agerelated conditions we currently label with one man's name as a singular noun. In the present moment with many countries and the World Health Organization (WHO) developing strategies for addressing dementia and AACC, it is essential to understand the complexities of the problem and mount an adequately broad social response that goes beyond reductionistic, falsely hopeful approaches. To have success, such plans must recognize not only the limitations of current approaches but also other global health challenges that we face like social injustice, economic turmoil, and global climate change with associated weather weirding (i.e., more variable and destructive meteorological events). Particularly today when social, economic, and ecological devastation threatens our communities and arguably even our species, we needed to think more deeply about the words we use to label problems and work diligently and honestly to enrich the sources of genuine hope in the stories that we create to imagine a viable future. Language is a powerful and everevolving force for social change as keywords can capture our imaginations, particularly when embedded in powerful stories. Some old words (like Alzheimer's and dementia) need reexamining and others (intergenerativity and ecopsychosocial, see below) perhaps employed to capture new realities.

\section{AN INTEGRATIVE APPROACH}

In this paper published in parallel in the Journal of Alzheimer's Disease (JAD) and the Journal of Intergenerational Relationships (JIR), I will argue that medicalization (i.e., making a complex social problem one to be addressed primarily through a medical model) and other social forces limit our current conceptions surrounding AD. They restrict the abilities of individuals and communities to imagine ways of addressing the complexities that the growing number of people with dementia in the world creates for us. We need new guidance from science but one that is less simplistic and more innovative and humble. Clinical care and research will likely be more effective if it is less discipline-based, i.e., interprofessional and transdisciplinary, and more open to integrative evolutionary systems thinking, e.g., ecopsychosocial models of health (Zeisel, Whitehouse et al, in preparation). At a social level, we need to rethink the concept of community and the relationships between humans and the rest of nature. Perhaps the dominant molecularly-oriented scientific establishment is slowly losing its grip on its messaging that has promised us solutions that are always just around the corner on the expensive march to progress. Fewer promising drugs are emerging from the pipeline that ostensibly runs from laboratory to the clinic. This notion that "cure" through genetic reductionistic medicine is our only (or at least main) hope needs to be challenged. So too we are converging on the idea that age-friendly, dementia-friendly, childfriendly, and environmentally-friendly communities are just overall healthier social forms for us all $[6,7]$.

An integrative primary care model embedded in community that empowers the self-efficacy of those 
that it serves is essential [8]. Prevention of chronic disease is becoming the watchword in efforts to reform health systems and in conditions that affect the aging brain. As a result, worlds of possibilities are opening up to us through public health and educational programs. Stories are more powerful in defining who we are as individuals and communities than our genes, and more easily modifiable through educational and cultural processes [5]. Intergenerational relationships in learning communities offer the best hope to create new stories that foster responsibility for each other, shared power, and a sustainable future [9]. The stakes are high. If we continue along a course dominated by uncritical scientism and unbridled capitalism with resultant hype and false hope, we will lose opportunities to take other paths that not only offer a better quality of life for those with dementia but for all of us. Science is powerful but a faith in scientific and technological solutions that goes beyond a reasonable extrapolation of existing capabilities becomes a form of religious dogma. The lessons found in efforts to reimagine and reinvent "AD" may provide keys to creating a greater collective wisdom about the transformation of aging, the role of brain science, and the reality of human interdependence [1]. Is aging best viewed as a lifespan process or an end stage of being old? Should we foster the independence of elders, but also recognize that we are all heavily dependent on each other? Such questions can encourage a collective wisdom that may be essential for human flourishing and perhaps even for survival.

To address AACC, we need to foster conversations among different fields, hence the bi-located presence of this article. JAD is a high impact largely scientific and clinical journal that rightfully prides itself on fostering different perspectives about dementia. JIR is for practitioners, researchers, and educators involved in intergenerational theory, program development, and replication. In my view, the development of intergenerational learning and health programs is the most effective response to the social challenges of $\mathrm{AD}$ and AACC. However, the discourse in $\mathrm{AD}$ is rarely lifespan- or educationally-oriented. As prevention and brain health become even more salient concepts, we might eventually come to conclusions such as improving public education is the best way of enhancing brain health and preventing "so-called" AD. Such system improvements could better educate the public about science, skepticism, and critical thinking which, in turn, could challenge the hegemony of often mystifying-to-lay-people messages of limitless scientific progress.

\section{CHALLENGING THE MYTH OF ALZHEIMER'S DISEASE}

In this article, I will summarize and criticize the latest attempts to organize our concepts of AD and related disorders in relationship to the new "diagnostic" guidelines that have been offered by the National Institute on Aging and Alzheimer's Association [10-12] and an International Working Group [13]. The main message from these two groups, although there are inconsistencies in the two approaches like the relative emphasis on memory impairment, is that many scientific breakthroughs have occurred and clear progress is being made toward a goal of cure or at least effective interventions to slow the disease. The claim from both groups is that we need biomarkers, including cerebrospinal fluid measurements and neuroimaging, to (eventually) diagnose AD earlier and more precisely. Once new more powerful drugs eventually emerge (a presumption not often challenged by the mainstream), we can get at the root of the biological processes when they first begin and treat people before symptoms appear.

The dominant view asserts that AD biology is a disruption in a single protein processing or perhaps a few linear chains of metabolic pathways. The most common view is that a cascade of toxic amyloid- $\beta$ formation is followed somehow by neuronal death and clinical symptoms and can be best arrested by a molecular pharmaceutical approach $[14,15]$. The considerable heterogeneity of the biological and clinical phenomenology is often weakly acknowledged. For instance, it is becoming more common to claim that $\mathrm{AD}$ is a "syndrome" rather than a specific disease, but the full implications of such diversity is rarely explored, i.e., how many different drug "cures" would we need to fix the problem? Most critically the mainstream defends the unproven idea that $\mathrm{AD}$ is unrelated to normal aging processes. By using the label of a "disease", medical science asserts the unexplored truism that early diagnosis and biological therapies represent our best areas of social investment. This is a powerful example of classic medicalization of a form of human suffering that leads to doctors and scientists becoming the main power brokers [16]. Quite simply the myth of $\mathrm{AD}$ is that it is a single disease quite separate from aging. It is neither in my view.

The new diagnostic criteria for $\mathrm{AD}$ and related conditions reveal the limits of medicalization. $\mathrm{AD}$ is heterogeneous at many levels from genes, to clinical features like rate of progression, and to social impact. It is intimately related to aging which is the main risk factor. Hence efforts to label people earlier and earlier 
with terms like "preclinical" or "Asymptomatic Alzheimer's disease" are fraught with dangers such as creating unwarranted concern and stigma [4, 17]. Further, many experts and laypersons believe these categories are of little use in the absence of specific therapies (which, although often promised, may never come). Also, the lack of strong association between clinical features and pathological features found at autopsy undermines the very idea of $\mathrm{AD}$ as a condition with a specific pathology. Autopsy findings are no longer definite but rather somewhat disengaged from the clinical phenomenology. For example, it is now well known that many people have plaques without dementia.

\section{ECOPSYCHOSOCIAL APPROACHES}

The limitations of current ways of conceptualizing and labeling cognitive issues in the lives of individuals and in the cultural space that medicine occupies in our lives also affects younger people. Giving children a diagnosis such as learning disability or attention deficit disorder can offer advantages in terms of access to services but can also create self-fulfilling prophecies of poor performance. Although labels can lead to developing individualized educational programs, they can also contribute to the overuse of medication.

What is needed for all ages is an ecopsychosocial approach to addressing the individual and social issues surrounding what we call AACC (Zeisel, Whitehouse et al, in preparation). Ecopsychosocial is an approach to health that builds on the concept of biopsychosocial but emphasizes the importance of a broader biological foundation to medicine (ecological and evolutionary) and also the key impact of the built and natural as well as social environment that more dramatically affect health than molecules and genes treated in isolation [18]. For example, infectious disease patterns that cause brain damage are changing because the warming associated with climate change is altering the distribution of the agents that spread the pathogens as well as the humans who are susceptible. Cognitively damaging neurotoxins like lead are still evident in our environment. When storms and floods hit communities, the elderly, especially those with dementia, are the most vulnerable. Head injuries in civilian and military life associated with wars, increasingly being fought over access to water and other natural resources, are a growing cause of dementia. Deeper, i.e., more purposeful, and broader, i.e., more community-based, ideas for promoting brain health are needed [19] built on an ecological view of biology in relationship to psychosocial factors that examines systems of interactions over time and space. Essentially we are calling for a public health focus on dementia to balance a more purely medical one. Such broader approach requires attention to genes and medications but also to education and urban design, such as creating organizations and public spaces to foster individual and community activity.

\section{INTERGENERATIVITY THROUGH INTERGENERATIONAL RELATIONSHIPS}

Whatever we might know or think we know or think we can know about the label AD, it is clear that these age-related cognitive impairments like dementia present formidable challenges and opportunities to intergenerational relationships [20-22]. The socalled dependency ratio reflects the growing number of "retired" elders who depend on the productivity of a shrinking number of younger people still in the work force. One might argue that dementia and cognitive impairment across the life course are the biggest challenges of all, especially when linked to the increasing economic and ecological challenges facing the next generations of human beings.

Care will first fall to the family if available and to younger generations in general, who are somehow able to both work and provide support to the increasing number of frail elders. How we frame issues like the responsibilities of one generation for another will be addressed through intergenerational conversations and social learning. Medicine and science can play a role in informing our decision making as long as they do not distort the truth and limit options as they are doing today. We need a health care and educational system that encourages a broader view of brain aging and intergenerational relationships [23, 24]. Environmental sustainability is a key intergenerational issue $[25,26]$. A guiding concept can be intergenerativity, i.e., a neologism meaning innovation through integration, going "between" idea and value spaces to create a sustainable future "beyond" [27, 28].

\section{THE INTERGENERATIONAL SCHOOL}

We need new organizational to teach us all to integrate scientific knowledge with other forms more effectively. The Intergenerational School is a high performing, public community charter school in Ohio that serves the educational needs of over 200 elementary 
school children and provides learning opportunities for hundreds of adults including elders some of whom have dementia [9, 27]. The school is an intergenerative learning organization built around principles of social construction, educational excellence, life-long experiential and service learning, and participation in social and political life. Its mission is to create a community that guides individuals in learning the skills and gaining experiences that foster life-long learning and spirited citizenship. Moreover, its vision is to assist other organizations and communities transform into multiage learning entities. The school fosters creative blends of thoughts and emotions by integrating domains of human knowledge and practice, like brain health, systems thinking through gardening, and collective wisdom through narrative. The use of the latest information technology, such as virtual reality and broad band connectivity, fosters the integration of the visual arts, music, dance, and other forms of scientific and humanistic expression through multimedia and community participation.

Educational achievement is not seen as a lock-step process that marches chronologically through various age-based placements for either children or adults. The younger students are part of developmentally appropriate classes where they may stay with the same teacher for several years. Advancement to the next stage is based on a developmental assessment of each child. Parent engagement is high. Report cards are based on school citizenship and values, as well as academic performance. A zero tolerance policy for aggression and a culture of mutual respect create a positive learning environment with little classroom disruption. Adult mentors connect through educational experiences that are meaningful to them including course credit, research theses, service learning, and legacy work. In other words the adult experiences are more varied and depend on the individual learning goals and/or degree requirements for a particular program. They are not guided by any state public education curriculum as the learning of the children is. The school's signature program is its reading mentor activities. As in most of its programs, the intergenerational learning occurs in pairs or small groups. Adults read to or listen to children read books from an extensive, richly intergenerationally themed library. But the students also share stories with elders about their lives sometimes using objects likes sports medals, awards, or photographs. The intergenerational learning is relationship-based. In the information technology sphere, the younger students may lead the elders in creating a PowerPoint presentation, developing their computer skills, or going beyond that old technology to, for example, recreate our garden in a private Second Life virtual reality space or use the Microsoft Kinect technology to exercise physically and mentally with each other.

Elders with dementia participate actively in the life of the school [29]. The volunteer of the year award was given a few years ago to an older adult who, while waiting to go on stage to receive her well-earned recognition, needed to be reminded, because of her severe short-term memory problem, that she came every week to read to the children. We have published qualitative and quantitative (a randomized controlled trial comparing peer group with school based social activities) studies demonstrating the value of learning in the school for elders with dementia. Lowered stress and enhanced sense of purpose and usefulness were part of the story of success [30].

On a regular basis, students visit long-term care facilities to engage with residents sharing various experiences to enhance brain health, like brain games and music. One such project had students interview residents from one partner facility (Judson Smart Living) about their role in protecting the local nature center in the 1960 s (now the Nature Center at Shaker Lakes), which our elders and students visit frequently, from a corrupt politician who wanted to put a freeway through it. These elders included some affected by short-term memory problems but who could still share their stories and inspire the youngsters to take on their own spirited citizenship and activist roles in their community. We self-published a book entitled "The Legacy of the Clark Freeway Fighters" with the student interviews, comments from community leaders, and rich picture illustrations of the intergenerational interactions in the nature center [31].

\section{INTERWELL}

From the beginning of the school in 2000, health, broadly defined as psychosocial well-being, has been a part of the educational environment. Now our team is developing an integrative primary care practice physically connected to the school which is itself moving to a new location in 2013. What features would an ideal model of a primary health program have? In Cleveland, we have used biomimetic principles, i.e., organismic holism with attention to ecosystem concepts and sustainability to design InterWell, an intergenerative model for practice that blends learning with individual and public health. 
Interdisciplinary and interprofessional partnerships have been a constant source of innovation, including many with individuals at Case Western Reserve University. Nursing has been key since the beginning of our school in 2000 because of its holistic approaches to learning, research, and practice. Nursing students have conducted service-learning projects like health screenings and community health events. Lead poisoning was the focus of one interprofessional project involving nursing, medical, and law students. Business school students helped build our permaculture Edible Forest Garden which supports our educational efforts about obesity and the individual and community value of local foods. Case Western Reserve University professors support our use of nursing models of care to enhance self-efficacy through the use of technology and continuous quality improvement. Social workers from Fairhill Partners, the current site of the school, promote evidence-based models of chronic disease self-management. Empowering individuals to take more responsibility for their own learning and health is a critical part of our model, as is developing a sense of community commitment. Although the practice model has not yet been fully implemented, elements are in place as described above.

\section{CHALLENGES AND OPPORTUNITIES}

In the beginning years of the school, lack of imaginative thinking on the part of our major organizations and leaders in our community has been the main barrier to our success. In the beginning, talking of a school designed for both children and elders provoked more blank stares and puzzled looks than offers to assist. Bureaucracies at every level try to force people into categories and boxes. Public school administrations and teachers' unions often seemed to conspire against children to promote adult interests. Standardized testing drains the positivity and passion out of learning. In Ohio as in many other states, the politics are complex. Republicans promoted charter schools but also encouraged testing to standards and unaccountable for-profit models of delivery of public education. Democrats did not have the courage to demand radical change in our existing public school systems. Larger educational and health organizations did not have the vision and courage to commit to innovations like our school with the fortunate exception of some local foundations. Huge social issues, like the aging of our society and global climate change, were often not adequately considered in community organization strategic planning.
Today we are finally seeing a shift in social attitude that should make a school committed to the impactful learning and health on people and the planet more valued.

\section{CONCLUSION}

The (relatively) simultaneous publication (with approval of the editors and peer-review for both journals) of this article JAD and JIR is an attempt to bridge the wide gap between the purviews and readership of both journals. Basic biological and clinical scientists need to appreciate the broader social challenges of AACC. Social program developers, educators, and researchers need to appreciate the power (and limits) of scientific methods. As a clinician and scientist, I see the strengths of a variety of approaches but the dominance of some forms over others. In my view, intergenerational education and health programs are key to addressing successfully AACC, particularly the problems of cognitive frailty in the elderly that we currently called $\mathrm{AD}$ in all its variants, but also for children with learning difficulties.

An intergenerational ethic of responsibility across the generations toward fostering a sustainable future for our species and life on the planet seems essential. Perhaps biological approaches such as drugs can make some difference to brain health and people's lives in the future, but hope seems to be waning for dramatic effects, because the therapeutic target is so complex. In the middle ground between molecular biology and social science lies information technology which is often undervalued in the medical world. Digital devices of all kinds connected to social networks provide ways of treating people clinically, fostering healthy intergenerational learning connections, and enhancing our thinking about tough social problems/opportunities, like AACC [16].

It would be better for our species if we practiced more humility and hence gained more wisdom about our abilities to address the complex problems that we have helped create. Perhaps we have exceeded some threshold for disability to deal with our collective activities of daily living (e.g., food production, the concept of "waste", and its disposition). Our ability to think about dynamic systems and to readjust our values away from material consumerism and toward sustainability and survival need enhancement. Information technology and new forms of multimedia learning that can help us address issues like global climate change and social injustice. These natural and political forces will likely 
dramatically change the landscape of human cognitive disabilities. Wars over natural resources and ecological disasters contributed to by global climate change will lead to more head injuries and changes in patterns of neurologically damaging infectious diseases.

Our true hope lies in creating more intergenerative learning organizations that enhance deeper thinking and richer ethical deliberation and help communities connect with each other and the world at large. Broad conceptions of ecopsychosocial health relevant to both individuals and natural and social communities should be at the heart of such educational enterprises and public health efforts. Incorporating intergenerative approaches in a health clinic that focuses on enhancing learning will hopefully lead to a cognitively and otherwise healthy greater number of informed and engaged citizens. Only through that process can we hope to turn our societies away from their currently unsustainable courses.

\section{DISCLOSURE STATEMENT}

The author's disclosure is available online (http:// www.j-alz.com/disclosures/view.php?id=1730).

\section{REFERENCES}

[1] Whitehouse PJ, George D (2008) The Myth of Alzheimer's, St. Martin's Griffin, New York

[2] Zeilig H (2013) Dementia as a cultural metaphor. Gerontologist, doi: 10.1093/geront/gns1203

[3] Whitehouse PJ, George DR (2011) Uncertain progress on the fuzzy boundaries of Alzheimer's disease: Reading between the guidelines. J Alzheimers Dis 26, 1-5.

[4] George DR, Whitehouse PJ, Ballenger J (2011) The evolving classification of dementia: Placing the DSM-V in a meaningful historical and cultural context and pondering the future of “Alzheimer's". Cult Med Psychiatry 35, 417-435.

[5] Whitehouse PJ, George D (2009) Banking on stories for healthier cognitive ageing. Lancet 373, 1166-1167.

[6] Stein J, Schettler T, Rohrer B, Valenti M (2008) Environmental threats to healthy aging with a closer look at Alzheimer's \& Parkinson's disease. Greater Boston Physicians for Social Responsibility and Science and Environmental Health Network, http://www.agehealthy.org/ccount/click.php?id=1

[7] Henkin N, Newman S (1985) The Best of You...The Best of Me: An Instructional Guide. Pennsylvania Department of Aging, Harrisburg, PA.

[8] Stange KC (2009) The problem of fragmentation and the need for integrative solutions. Ann Fam Med 7, 100-103.

[9] Whitehouse PJ, Bendezu E, Fallcreek S, Whitehouse C (2000) Intergenerational community schools: A new practice for a new time. Educ Gerontol 26, 761-770.

[10] Albert MS, DeKosky ST, Dickson D, Dubois B, Feldman HH, Fox NC, Gamst A, Holtzman DM, Jagust WJ, Petersen RC, Snyder PJ, Carrillo MC, Thies B, Phelps CH (2011) The diagnosis of mild cognitive impairment due to Alzheimer's disease: Recommendations from the National Institute on
Aging-Alzheimer's Association workgroups on diagnostic guidelines for Alzheimer's disease. Alzheimers Dement 7, 270-279.

[11] McKhann GM, Knopman DS, Chertkow H, Hyman BT, Jack CR, Jr., Kawas CH, Klunk WE, Koroshetz WJ, Manly JJ, Mayeux R, Mohs RC, Morris JC, Rossor MN, Scheltens P, Carrillo MC, Thies B, Weintraub S, Phelps $\mathrm{CH}$ (2011) The diagnosis of dementia due to Alzheimer's disease: Recommendations from the National Institute on Aging-Alzheimer's Association workgroups on diagnostic guidelines for Alzheimer's disease. Alzheimers Dement 7, 263-269.

[12] Sperling RA, Aisen PS, Beckett LA, Bennett DA, Craft S, Fagan AM, Iwatsubo T, Jack CR, Jr., Kaye J, Montine TJ, Park DC, Reiman EM, Rowe CC, Siemers E, Stern Y, Yaffe K, Carrillo MC, Thies B, Morrison-Bogorad M, Wagster MV, Phelps CH (2011) Toward defining the preclinical stages of Alzheimer's disease: Recommendations from the National Institute on Aging-Alzheimer's Association workgroups on diagnostic guidelines for Alzheimer's disease. Alzheimers Dement 7, 280-292.

[13] Dubois B, Feldman HH, Jacova C, Cummings JL, Dekosky ST, Barberger-Gateau P, Delacourte A, Frisoni G, Fox NC, Galasko D, Gauthier S, Hampel H, Jicha GA, Meguro K, O'Brien J, Pasquier F, Robert P, Rossor M, Salloway S, Sarazin M, de Souza LC, Stern Y, Visser PJ, Scheltens P (2010) Revising the definition of Alzheimer's disease: A new lexicon. Lancet Neurol 9, 1118-1127.

[14] Smith MA, Atwood CS, Joseph JA, Perry G (2002) Predicting the failure of amyloid-beta vaccine. Lancet 359, 1864-1865.

[15] D'Alton S, George DR (2011) Changing perspectives on Alzheimer's disease: Thinking outside the amyloid box. $J$ Alzheimers Dis 25, 571-581.

[16] George DR, Whitehouse PJ (2011) Marketplace of memory: What the brain fitness technology industry says about us and how we can do better. Gerontologist 51, 590-596.

[17] George DR, Qualls SH, Camp CJ, Whitehouse PJ (2012) Renovating Alzheimer's: "Constructive" Reflections on the New Clinical and Research Diagnostic Guidelines. Gerontologist, doi: 10.1093/geront/gns 1096

[18] Whitehouse P, George D (2010) The aesthetics of natural elderhood. J Aging Humanit Arts 4, 292-301.

[19] Whitehouse P (2010) Taking brain health to a deeper and broader level. Neurol Inst J 3, 17-22.

[20] Jarrott SE, Bruno K (2003) Intergenerational activities involving persons with dementia: An observational assessment. Am J Alzheimers Dis Other Demen 18, 31-37.

[21] de Souza EM, Grundy E (2007) Intergenerational interaction, social capital and health: Results from a randomised controlled trial in Brazil. Soc Sci Med 65, 1397-1409.

[22] Gigliotti C, Morris M, Smock S, Jarrott SE (2005) An intergenerational summer program involving persons with dementia and preschool children. Educ Gerontol 31, 425-441.

[23] Ingman S, Benjamin T, Lusky R (1999) The environment: The quintessential intergenerational challenge. Generations 22, 68-71.

[24] Hayes CL (2003) An observational study in developing an intergenerational shared site program. J Intergener Relatsh $\mathbf{1}$, 113-132.

[25] Kaplan M (2004) Generations United for Environmental Awareness and Action. United G, Washington, DC.

[26] Stenig S, Butts D (2010) Generations going green: Intergenerational programs connecting young and old to improve our environment. Generations 33, 64-69. 
[27] George D, Whitehouse C, Whitehouse P (2011) A model of intergenerativity: How the intergenerational school is bringing the generations together to foster collective wisdom and community health. J Intergener Relatsh 9, 389-404.

[28] Whitehouse PJ, Ritchey C, Schiller B, Willoughby MG (2009) Intergenerativity: Learning "between" to create the sustainable "beyond". World Appreciative Inquiry Conference, Nepal.

[29] George DR, Whitehouse PJ (2010) Intergenerational volunteering and quality of life for persons with mild-to-moderate dementia: Results from a 5-month intervention study in the United States. J Am Geriatr Soc 58, 796-797.

[30] George DR, Singer ME (2011) Intergenerational volunteering and quality of life for persons with mild to moderate dementia: Results from a 5-month intervention study in the United States. Am J Geriatr Psychiatry 19, 392-396.

[31] Harris D, Whitehouse PJ (2011) The Legacy of the Clark Freeway Fighters, Tec4Life, Cleveland, OH. 